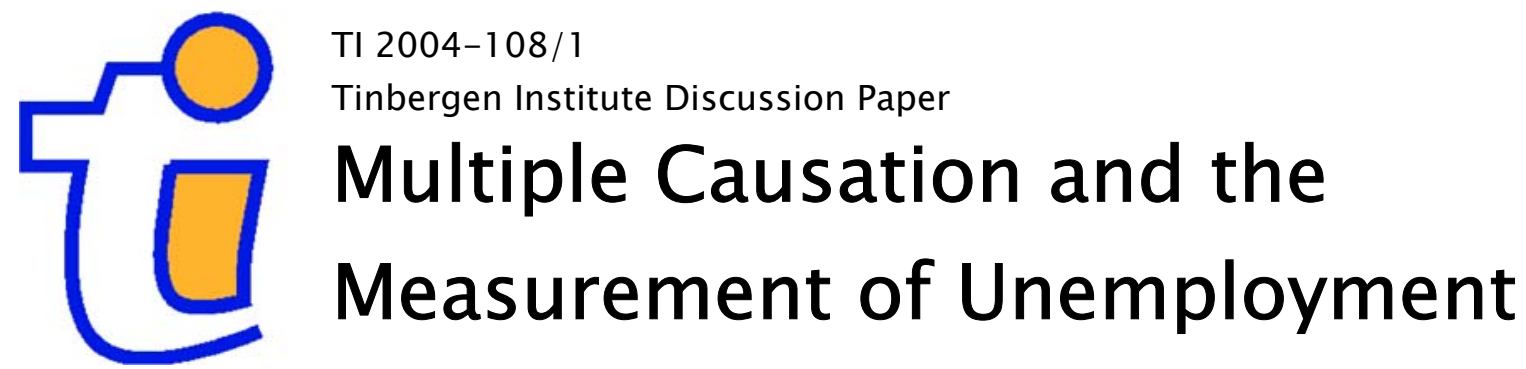

Peter Rodenburg

Department of Economics and Econometrics, University of Amsterdam, and Tinbergen Institute. 
Tinbergen Institute

The Tinbergen Institute is the institute for economic research of the Erasmus Universiteit Rotterdam, Universiteit van Amsterdam, and Vrije Universiteit Amsterdam.

Tinbergen Institute Amsterdam

Roetersstraat 31

1018 WB Amsterdam

The Netherlands

Tel.: $\quad+31(0) 205513500$

Fax: $\quad+31(0) 205513555$

Tinbergen Institute Rotterdam

Burg. Oudlaan 50

3062 PA Amsterdam

The Netherlands

Tel.: $\quad+31(0) 104088900$

Fax: $\quad+31(0) 104089031$

Please send questions and/or remarks of nonscientific nature to driessen@tinbergen.nl.

Most TI discussion papers can be downloaded at http://www.tinbergen.nl. 


\title{
Multiple Causation and the Measurement of Unemployment
}

\author{
Peter Rodenburg * \\ Department of Economics and Econometrics \\ University of Amsterdam \\ Roetersstraat 11 \\ 1018 WB Amsterdam \\ The Netherlands \\ Tel: 0031 20-525 7344 \\ E-mail: P.Rodenburg@uva.nl \\ http://www.fee.uva.nl/hme/
}

\begin{abstract}
The establishment of appropriate policy measures for fighting unemployment has always been difficult since causes of unemployment are hard to identify. This paper analyses an approach used mainly in the 1960s and 1970s in economics, in which classification is used as a way to deal with such a complex, multiple causal phenomenon like unemployment. The method is based on decomposing unemployment into classes of unemployment and the measurement of each of these classes by reference to stable, measurable macroeconomic relationships like the Phillips curve and the Beveridge curve. In this way economists were able to 'diagnose' unemployment and make policy recommendations for fighting unemployment without making explicit reference to the underlying singular causes of unemployment.
\end{abstract}

Keywords: Classification of unemployment, Causality, Theories of unemployment, Phillips curve, Beveridge curve, Economic policy measures

JEL-classification: B, E, J

\footnotetext{
* This paper was presented at the conference "Causation and Explanation in Natural and Social Science" (CENSS) in Ghent, Belgium, 15-18 May 2002, and the expert workshop "Measurement in Economics and Natural Sciences" of the LSE-Amsterdam Measurement Group, in Amsterdam, Holland, 13-14 May 2002. I would like to thank the organisers and participants of both meetings, and particularly Kevin Hoover, Sang Yi, Harro Maas and Mary Morgan for their helpful comments and questions.
} 


\section{Introduction}

Instances of multiple causation have proved to be difficult to deal with for both scientists in the field and philosophers. In economics, unemployment is one such instance, and though economists use different methods of analysis like aggregate supply and demand analysis, microeconomic models, and econometrics, causal explanations of unemployment are not easy to produce. The exact underlying cause or causes of unemployment can seldom be identified separately and the explanations are often surrounded by a set of auxiliary assumptions.

The main aim of this paper is to investigate how economists, faced with this problem of identifying causes of unemployment and the need for real world economic policy recommendations, attempted to circumvent this problem of multiple causation of unemployment, and how they provided a method of diagnosing unemployment. This method is based on decomposing unemployment into classes of unemployment and the measurement of these classes without explicit reference to their underlying singular causes.

This method is not the result of deliberate considerations of economic theorists but rather the result of attempts of individual economists acting independently in order to operationalise concepts, originating from economic theory, and mainly for the sake of economic policy purposes. This approach resulted in a series of articles in the period in which macroeconomic thinking dominated economics. The approach really took off after the establishment of the Phillips curve and the UV or Beveridge curve, both in 1958, and was used intensively in the discussions on high unemployment in the United States throughout the 1960s.

Since this approach is based on rather ad-hoc attempts to measure economic concepts, it has been quite overlooked in both economic and methodological literature and, as a consequence, no official name has been given to this approach. In this paper it is referred to as the 'classification approach'.

The paper will proceed as follows. Section 2 will analyse unemployment as a multiple causal phenomenon and look at the way economists and philosophers deal with these cases. Section 3 discusses how classes of unemployment come into existence. It deals with the distinction between classification and division. Section 4 deals with the measurement of classes of unemployment. Section 5 analyses the results of measurement while section 6 discusses the inference we can make concerning policy measures. Finally, in section 7, conclusions are drawn. 


\section{The difficulty of finding causal explanations for unemployment}

Unemployment can be considered as a phenomenon driven by multiple causes. For example, unemployment is attributed to deficient aggregate demand, technical progress, immobility of labour, costs of information, the rise and fall of industries, trade union power, seasonal nature of jobs, etc., or combinations of these factors. These causes act independently, and unemployment therefore arises "because a number of factors are balanced against one other in a particular way. To speak of the state of one of these factors as the cause, or even $a$ cause, is arbitrary" (Pigou, 1933:27). This makes clear that unemployment is a mixture of effects of these singular causes. However, recognition of unemployment as a multiple causal phenomenon has far reaching consequences both for the way the effect of a singular cause on unemployment can be identified and for how causal explanations of unemployment can be provided. Since economists don't have laboratories in which they can study the effect of singular causes in isolation, they have to rely on other measurement strategies. Strategies for the measurement of the effect of a singular cause have been developed both in economics and the philosophy of science.

In his System of Logic (1843), John Stuart Mill suggested decomposing these multiple causes into singular causes and to analyse their resultant effect as - put in modern terminology - the "vectorial sum" of the individual causes involved. The outcome effect can physically be thought of as a parallelogram of effects. However, how exactly to isolate singular causes in a case of multiple causation he left unclear, since his four inductive methods fail to disentangle multiple causal phenomena. And since indefinitely many sets of possible sets of singular causes can all produce the same resultant outcome effect of unemployment, causal explanations of unemployment are hard to establish.

In economics, one of the most important strategies to measure the effect of a cause is the use of econometric analysis. In econometric analysis the strength of (multiple) individual causes in measured statistically. Though econometric analysis turned into a non-causal measurement strategy in the second half of the $20^{\text {th }}$ century, early contributors to econometric analysis like Jan Tinbergen considered it as a causal analysis (Morgan (1990), Boumans (1992), Hoover (2001)). Multiple regression analysis is widely used in economics, but is not employed in the case of unemployment. Many studies can be found that try to estimate the effects of a singular cause on unemployment, like for example the effect of technical progress, immobility of labour or union power, but no multiple regression analysis can be found where the summed outcome effect of a set of underlying, individual causes on unemployment is 
measured directly in a multiple regression equation. One reason might be that the underlying causes, like technical progress, immobility of labour or union power, etc., are themselves hard to measure. But the main reason seems to be of another order. Unemployment is considered so complex a phenomenon that it is best studied in a system of interdependencies, in which supply and demand for labour determine the level of employment and unemployment is a considered as a 'residual' category. This approach to unemployment is already paramount in pre-econometric, economic literature. Pigou (1933) for example, argues that: "What we have to look for, therefore, is not a sum of separate causes of unemployment, each accountable for so much of it, but rather a system of interconnected factors jointly responsible for the whole of it" (Pigou, 1933: 28). Therefore, unemployment is analysed in a supply and demand framework and it is the set of variables determining supply and demand for labour (and the way supply and demand interact) that is analysed, rather than unemployment directly. Consequently, unemployment is a derived quantity, and the effect of individual causes is measured indirectly.

Following Pigou, the consequence of this approach is that: "Attempts to disentangle the causation of unemployment must be directed, not towards one but towards two objectives. We wish to discover, if we can, why the unemployment that exists at any time does exist and also why the amounts of it that exist are different at different times" (Pigou, 1933: 26). The change in unemployment is analysed by imposing the ceteris paribus clause in a comparative static analysis. "The difference between the two quantities is clearly the result of the difference between the two complexes. This difference may consist in a single item. If it does, we are able to find for a change in unemployment a single cause (..)" (Pigou, 1933: 28). However, in the real world, one cannot be sure that no other causes turn up that affect the total outcome.

Given these difficulties to identify the separate causes of unemployment, it is no surprise to see that other approaches were used in labour economics. For example, in the 1970s microeconomic models of unemployment came into fashion. These models can be considered as formal representations of certain partial mechanisms operating in the labour markets. ${ }^{1}$ Search models of unemployment for instance, model the search behaviour of individual agents in situations of non-deficient demand for labour. Obviously, this is not the only mechanism governing unemployment in the labour market since situations of deficient demand do occur. Other mechanisms are therefore explored in other, often competing, models. Since these

\footnotetext{
${ }^{1}$ Machamer et al. $(2000,7)$ define a mechanism as "entities and activities organized in such a way that they are | productive of regular changes from start or set-up to finish or termination conditions".
} 
models represent a mechanism, the causal chain is not immediately clear. One cannot assume that the causes are in the objects or entities but, as Machamer et al (2000) put it, "only the whole set of entities and activities can account for the causes of a phenomenon". And this is precisely what these micro models do: describe the entities and activities of a mechanism. The use of micro models of unemployment can thus be understood as a way to give a 'mechanism' account of causes of unemployment without separating out the exact individual causes.

The classification approach, as discussed in this paper, can be seen as another approach to the question of how to deal with multiple causation.

\section{Classifications of Unemployment}

Unemployment has been classified in many different ways in economics. Hughes and Perlman (1984: 26) for example, make note of no fewer than 70 different types of unemployment in the economic literature. Most of these different classes are completely or partially incompatible or incommensurable with each other, and economists reckon that no single classification can be considered as the definite or true one. This plain fact about classes of unemployment raises many questions. Why do there exist so many different classes of unemployment? How do these classes come about? And what role do they play in the explanation of unemployment? Let's start with analysing how classes of unemployment come into existence in the first place. Classes of unemployment come into existence, basically as the consequence of two different approaches of inquiry: an inductive, empirical approach and an analytical, deductive approach.

\section{Classification}

In the inductive, empirical approach, data of particular unemployed are collected, usually through surveys or establishments like labour exchanges, and grouped, classified or processed, in such a way that new classes of unemployment come into existence, where the members of each group share the same characteristics or properties. Examples are classes like 'long term unemployment', 'unemployment in the manufacturing industry', 'unemployment among highly educated workers', etc. The process by which data are ordered or "put together" from particular to universal, is called 'classification' (Benjamin: 1925). ${ }^{2}$ The main purpose of a classification is, according to Sokal "to describe the structure and relationship of the constituent objects to each other and to similar objects, and to simplify these relationships in 
such a way that general statements can be made about classes of objects" (Sokal: 1974, 1116). One reason for classification is that we think that the classes represent the "natural" structure of the world from which we hope to learn the laws governing the behaviour of the objects (Sokal: 1974, 1116). ${ }^{3}$ Another reason for invoking separate classes is the imposition of external constraints on the data, for example by institutions or administrative reasons. Thus, classification is directed by the possibility or the desire to classify data of unemployment into separate categories, and unless one is able to find a "natural" classification, classifying is a subjective matter in which we rely on conventions and definitions of the objects.

In classification, there seems little or no place at all for causal notions. Statistical offices try to reduce the theoretical content, and hence causal notions of concepts as much as possible. Most of the classes invoked by the process of classification seem to be social or linguistic conventions, and the 'underlying cause' of the unemployment in these classes is not clear. The class 'unemployment in the building industry' for example seems not to have a meaningful causal notion. The building industry could be defined in another way, but changing the definition wouldn't be more revealing about the 'causes' of this class. The problem is rather to find an appropriate definition for the building industry than to find the underlying causal notion. We can therefore think of the classes invoked by such classification as being 'non-causal' classes. Hughes and Perlman refer to the classes obtained from the process of classification as a 'statistical' classification (Hughes and Perlman: 1984, 26).

\section{Division}

The second approach is the analytical, deductive approach. In this approach, classes of unemployment are derived from a specific economic theory and are called into existence in order to denote the causes and nature of unemployment. Since many different analytical approaches have been applied to the problem of unemployment, many different theoretical

${ }^{2}$ It is also frequently used to denote the result of classification itself. Thus, the result of classification is a classification (Sokal: 1974, 1116). The term 'classification' is in this paper used for both the process of classification and the outcome of this process.

${ }^{3}$ Three stands on classification can be distinguished: naturalism, modified conventionalism and radical conventionalism (Hollinger: 1976, 319). The first view, naturalism, seeks for a "natural" classification of objects belonging to natural kinds, i.e. objects with essential properties. The second view, modified conventionalism, states that a classification of natural kinds alone is impossible, both because, the "real essence" of objects is unknown and because of human interests. As a consequence, a classification is at least partly, a social or linguistic convention and hence subject to subjective judgements. Radical conventionalism finally, rejects the that a meaningful distinction between 'natural' and 'conventional' can be made, and claims therefore that all classifications are conventions of some sort.

\begin{tabular}{|l|}
\hline Deleted: that \\
Deleted: since \\
Deleted: At least part of the \\
Deleted: therefore \\
Deleted:
\end{tabular}


classes of unemployment have been invoked as well, like for example 'Keynesian', 'Marxian', or 'Classical unemployment'. This process of going from a universal to particulars, is called 'division' (Benjamin: 1925). "Division means the process of specifying or enumerating the individual members of a class" (Benjamin: 1925, 459), and therefore makes clear which subgroups with the same properties are implicit in any class. This is the converse of the strict meaning of the term 'classification'. An aggregate object or quantity is "analysed" or "broken up" in smaller subsets of objects, which have the same characteristics or properties in common. The outcomes of this process are identifiable as particulars. Therefore, Benjamin refers to this process as 'particularisation'. In economic literature, the term 'decomposition' is more often used instead of division (see for example, Muysken, 1989). ${ }^{4}$

Division can be made without causal notions, for example when I divide tables in a room in two classes, walnut and mahogany. However, in the case of unemployment, division is mainly based on causal notions, contrary to classification of unemployment (where causal notions play only a limited role if any role at all). The classes are derived from economic theories which implicitly or explicitly contain a set of one or more individual causes. Milton Friedman (1968) for example is explicit about the singular causes of the class 'natural rate of unemployment'. He describes the natural rate of unemployment as the unemployment rate: "That would be ground out by the Walrasian system of general equilibrium equations, provided that there is embedded in them the actual structural characteristics of the labour and commodity markets, including market imperfections, stochastic variability in demands and supplies, the costs of gathering information about job vacancies and labor availabilities, the costs of mobility, and so on" (Friedman, 1968: 8). He obviously sees these latter factors as the set of individual, underlying causes of the natural rate of unemployment. Theoretical notions about causation can also be found in other classifications, though they might be implicit. Economists refer to this kind of classification as a classification on a 'causal' or 'ex-ante' basis (Thirlwall: 1969, 22), or as an 'analytical' classification (Hughes and Perlman: 1984, 26).

Though classification and division are presented here as strictly distinct approaches, this distinction is not always clear in practice. First of all, as is often the case, some exceptions or in-between cases can be found. 'Seasonal' unemployment for example, seems to fit best in the 'causal' classification, since there are implicit notions about its (set of) cause(s). It is however sometimes determined inductively, i.e. by classification, and it is not derived from

\footnotetext{
${ }^{4}$ In the remainder of the paper the outcome of the process of division is referred to as a 'classification' too, which may seem confusing but is more in line with economic literature.
} 
any specific economic theory. Secondly, in some instances division is only possible when classification precedes division. The classes in which we can divide tables in a room for example, depends upon the classes we have established by classification. For unemployment, this is case when one wants to break up unemployment by duration. In these cases (thus without causal notions) "one never divides a class into sub-classes without at the same time looking over the different sorts of objects which might be put into these sub-classes, i.e. classification" (Benjamin, 1925: 461).

Finally, the distinction between classification and division is hardly made in economic literature: The term 'classification' is used for both division and classification.

\section{The main classes of unemployment for economists}

Before analysing the role of classes of unemployment, some of the main classes of unemployment will be discussed that have dominated discussions in labour economics since the late 1930s. Since the purpose is only to show the coexistence of different classification schemes in economic literature, and not to provide a detailed account of all classes, these classes will be discussed here only briefly. For a detailed description of classes of unemployment see, for example, Muysken (1989).

In economic literature, at least four important distinct classification schemes can be distinguished. Probably the most important classification is the so-called 'traditional' classification: the decomposition of unemployment into frictional, structural and deficientdemand unemployment. This classification played an important role in the debates in the $1950 \mathrm{~s}$ and especially in the 1960s when the USA faced a relative high unemployment rate, (though frictional unemployment was sometimes interpreted as a subclass of structural unemployment). Deficient demand unemployment typically occurs when an economy is in recession and investment and consumption expenditures fall. Frictional unemployment is the result of the process of job seeking. Since it takes some time to form a match between an unemployed person and a vacancy, some level of unemployment is inevitable. Frictional unemployment is therefore considered as a short-term phenomenon. Structural unemployment occurs when a qualitative mismatch occurs between unemployed and vacancies: The skills of the worker and the job requirements do not match. Since the only way to cure this type of unemployment is by retraining of workers, it is considered as a long-term phenomenon. The idea of deficient demand unemployment was obviously introduced with Keynes' General Theory. The idea of 
frictional and structural unemployment existed before then, and can be found, for example, in Beveridge (1909).

Other classifications that are important are the distinction between 'Keynesian' and 'Classical' unemployment (Keynes-Pigou, after 1937) and the related distinction between 'voluntary' and 'involuntary' unemployment (Keynes-Pigou). ${ }^{5}$ The issue at stake here is whether the wage level corresponds to the equilibrium wage level. In case the wage level is above the market clearing wage, 'Classical' unemployment arises which is basically voluntary in nature, since workers could have accepted lower wages. However, Keynes argued that aggregate demand for labour falls short and that it was not in the power of workers to reduce unemployment. Hence he considered it mainly as an involuntary phenomenon. Malinvaud (1977) uses the Keynesian-Classical distinction in his disequilibrium approach, too. Finally, an important distinction between 'natural' and 'non-natural' unemployment was introduced by Friedman (1968) and Phelps (1967). Likewise, modern microeconomic models of unemployment invoke other classes of unemployment, like search unemployment or 'queue' unemployment. Yet, these classes do not form an encompassing classification scheme, like the previous ones.

The classes of unemployment described here basically fall in two categories; classes that we can think of as "equilibrium" unemployment and "disequilibrium" unemployment. Though classes like 'Classical', 'Natural', 'frictional', 'structural', 'NAIRU' and 'voluntary' unemployment have different definitions and interpretations, they all have in common the idea of a level of unemployment at which the labour market (and financial markets) are in equilibrium. Classes like 'deficient demand', 'Keynesian', 'cyclical', 'Marxian', 'involuntary', or 'non-natural' unemployment stress the relevance of disequilibria between supply and demand for labour. This distinction between "equilibrium" and "disequilibrium" has been the main issue in debates on unemployment, witnessed by the 'structural'-'deficient demand' debate in the US in the 1960s and the recent discussion in macroeconomics on sectoral shifts vs. aggregate demand shocks. ${ }^{6}$

\footnotetext{
${ }^{5}$ The idea of involuntary unemployment became significant when Keynes used it in Chapter 2 of The General Theory of Unemployment, Interest and Money. Marshall (1890), Pigou (1914) as well as Wicksell (1907) and Cassel (1902) used the term before (Boianovsky and Trautwein: 2003).

${ }^{6}$ See for example Brainard and Cutler (1993), Sectorial Shifts and Cyclical Unemployment Reconsidered, The Quarterly Journal of Economics, Vol. 108, No. 1. pp. 219-243.
} 


\section{The Role of Classification in Explanations}

The main role of classifications seems to be based on heuristic reasons: to denote the causes and nature of unemployment. Muysken for example argues that: "The analytical relevance of a classification of unemployment lies in its identification of the constraints to full-employment" (Muysken: 1989, 417), where the term 'constraint' seems to refer to a set of unspecified, singular causes of unemployment that prevent the economy from reaching full employment. ${ }^{7}$

However, in the era of macroeconomic analysis of unemployment, these classes of unemployment were not only used for heuristic reasons. Attempts were undertaken by economists to measure analytical classes of unemployment. Measurement of entire classes of unemployment could indicate their size and relevance and consequently, could direct the design of appropriate measures to reduce unemployment. Unfortunately, the 'analytical' or 'causal' classes of unemployment do not correspond with the 'statistical' classes obtained from the process of classification. Quantification of analytical classes is far from easy, and economists therefore developed an indirect way of measuring these classes.

In an analytical class, singular causes are grouped together and labelled with one generic and collective noun. An analytical class is thus affected by a whole set or cluster of causes, and by assigning numbers to this analytical class the total outcome effect of a set of grouped causes on unemployment is measured all together, rather than that the effect of a singular cause on unemployment is measured individually. This process of grouping of causes in clusters is presented in figure 1. Economic theories provide economists with a particular framework for breaking up unemployment in different, analytical classes of unemployment, resulting in a causal classification scheme that consists of a set of supplementary classes. However, several classification schemes can be found in economic literature, and the classes of unemployment they refer to are usually incompatible or incommensurable. The most relevant classification schemes for economists are mentioned here (classification schemes A-E). Each analytical class within each scheme suggests a set of singular underlying causes (S1-S3). 'Frictional unemployment' for example, is associated with underlying, singular causes like immobility of labour, incomplete information about existing vacancies, the duration of the job application process and the like. All these causes are grouped together as 'friction'. For the

\footnotetext{
${ }^{7}$ The concept of 'full employment' however is subject to causal notions itself. In economics 'full employment' is not considered as the complete absence of unemployment but rather the occurrence of a certain level of unemployment, that appears for certain reasons. William Beveridge (1944) for example, considered full employment to be at a $3 \%$ level (pp.127-128). According to him it was made up of: $1 \%$ seasonal unemployment, $1 \%$ change of employment, and $1 \%$ frictional unemployment.
} 
exact determination of the singular causes in the set or cluster of causes there are however no clear-cut rules. Obviously, the particular economic theory provides some guidelines but apart from that it seems to be a matter of economic intuition or convention, making the determination of the set of underlying causes in some sense arbitrary.

S 1

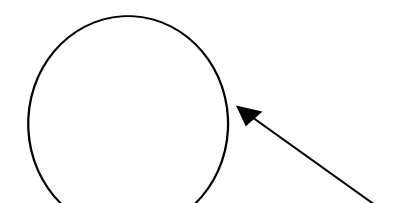

S 2

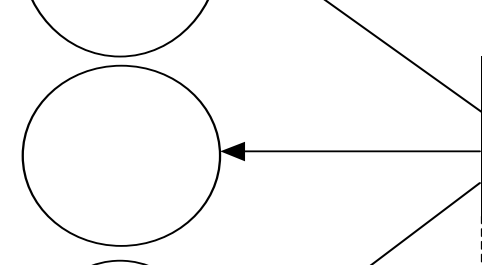

S 3

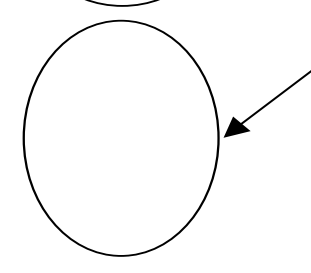

A

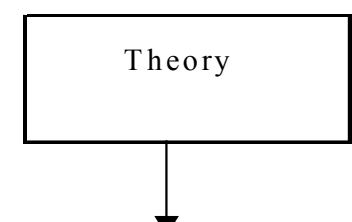

Causal

classification

scheme

B

\begin{tabular}{|l|}
\hline Natural \\
\hline Unnatural \\
\hline
\end{tabular}

Friedman $(1968)$

$\mathrm{C}$

Voluntary Involuntary

$\mathrm{D}$

\begin{tabular}{|l|}
\hline Keynesian \\
\hline Classical \\
\hline Seasonal \\
\hline Frictional \\
\hline Change of employm. \\
\hline
\end{tabular}

Keynes/Neoclassical (1937)

Keynes/Pigou (1937)

Malinvaud (1977)

Beveridge (1944)

Figure 1: 'Clustering' of causes for different classification schemes

Unspecified singular causes might also affect multiple analytical classes simultaneously. The singular cause 'technological progress' for example can make workers in a particular sector redundant and hence cause structural unemployment. However at the same time it might lower, for example, frictional unemployment (for instance because it lowers the costs of obtaining information). This singular cause should therefore be part of the set of underlying causes of both structural unemployment and of frictional unemployment, for instance be in set S1 as well as in S2. Finally, analytical classes are measured. This will be discussed in the next section. 


\section{$4 \quad$ Measurement of analytical classes of unemployment}

In order to establish appropriate policy measures to fight unemployment, one would like to know the nature of unemployment. The problem of identification of the nature of unemployment is therefore very important for economists and can be found treated in literally hundreds of publications in economic literature. Unfortunately, the 'causal' or analytical classes of unemployment are not very useful in this respect. The measurement of analytical classes is problematic for two reasons. The first reason is that for some analytical classes the definitions are unclear and division has to take place based on unobservable properties. The distinction between voluntary and involuntary unemployment, for example, seems extremely fuzzy, especially since it is defined in a macroeconomic way (Keynes) as well as in a microeconomic (neoclassical) way. The two definitions are incompatible and neither is operational; the properties of involuntariness are not directly observable. Lucas expresses this fuzziness as follows: "There is an involuntary element in all unemployment in the sense that no one chooses bad luck over good; there is also a voluntary element in all unemployment in the sense that however miserable one's current work options, one can always choose to accept them" (Lucas: 1981, cited in Hughes and Perlman, 1984, 34). Hughes and Perlman $(1984,32)$ therefore argue that the problem is that "the various categories of unemployment are not always as distinct and separate as has been suggested". As a consequence one cannot assign numbers to 'causal' classes of unemployment. In the words of Hughes and Perlman: "Although conceptually it is possible to distinguish between the various types of unemployment (..), it is not possible to assign individuals to these categories. That is, it is not possible to say individual A is frictionally unemployed, while individual B is structurally unemployed and C is cyclically unemployed" (Hughes and Perlman: 1984, 32).

However, there is a second reason why analytical classes are not measurable, which relates directly to the method of division. Not all definitions of analytical classes are vague as Hughes and Perlman suggest, or lack operational definitions. Classes like 'frictional' and 'structural' unemployment are in fact well defined. Frictional unemployment for example is defined as "those unemployed for whom jobs are available within reasonable reach, which are reasonably suited to their skills and pay current wage levels" (Gilpatrick: 1966, 202). Workers that are not qualified for the job vacancy are considered as structurally unemployed. These definitions can in principle be used empirically or made operational. Frictional unemployment for example could be determined as the number of possible matches between registered 
unemployment and registered vacancies in a particular area at a labour exchange. The problem is rather that these classes lack a meaningful operational definition when using the process of division. The definitions of classes like 'voluntary', 'involuntary', 'frictional' and 'structural' unemployment require data at the level of individual workers such as knowledge about skills of individual workers, about individual job requirements or about rejection of job offers of individual workers. And because total unemployment or unemployment rates are aggregated quantities in which this qualitative information about the characteristics of particulars (unemployed and vacancies) is not available, one cannot assign numbers to particulars. ${ }^{8}$ As Benjamin put it: "Since deduction is simply a matter of relationship between classes, this form of reasoning can never give us a particular unless that particular is first inserted as a datum into the reasoning process" (Benjamin, 1925: 462). Division using only aggregate, quantitative data of unemployment is therefore an unsuitable means to provide measures of its classes in the case of unemployment, whether definitions of classes are operational or not. As a consequence, we cannot operationalise the large majority of 'causal' classes of unemployment in a measurement procedure and directly measure the nature of unemployment in a meaningful way.

A solution has been sought to this problem. It has been found in the following approach (to which Thirlwall refers as the 'American' approach (p.24)), which measures the causal classes indirectly. For most classes, two steps have to be taken. The first step contains the search for stable, measurable, macroeconomic relationships. Over the years, economists thought they had found these invariant relationships in the Phillips curve and the UV or Beveridge curve. ${ }^{9}$ The (modified) Phillips curve represents the relation between inflation and unemployment, while the Beveridge curve represents the relation between vacancies and unemployment. Both relations are macroeconomic relations and are plotted with directly measured values of inflation, vacancies and unemployment. A few classes of unemployment can be measured directly by using these relationships. The class 'NAIRU' for example is defined as the level of unemployment that is consistent with a stable rate of inflation, and is represented as the intersection of the Phillips curve with the horizontal axis, where the level of inflation is zero. Thus, once one has constructed the Phillips curve for an economy, one has measured the class 'NAIRU'.

\footnotetext{
${ }^{8}$ Qualitative data about job requirements and skills of workers are available at labour exchanges. However, this qualitative data gets lost in the process of aggregation of unemployment or by only taking samples of unemployment. 9 Later research revealed shifts of both the Phillips curve and the Beveridge curve (Rodenburg, 2002). This problem, however relevant, is ignored in this paper.
} 
Other classes of unemployment need a second step in order to be measurable. As we saw, some of the most important 'causal' classes of unemployment, like 'voluntary', 'involuntary', 'frictional', 'structural' etc., need information at the level of particulars (individual worker and vacancy). In the absence of the necessary qualitative data, the only way to operationalise these classes is to redefine them in such a way that information about particulars is no longer necessary, i.e. so that these classes can be interpreted in a macroeconomic framework. They can then be measured with reference to the stable, macroeconomic relationships. This was the case for the classes 'frictional' and 'structural' unemployment in the 1960s. Economists tried to quantify 'structural' unemployment both with the Phillips curve and the Beveridge curve, changing in both cases the definition and meaning of 'structural' unemployment.

Dow and Dicks-Mireaux (1958) established the UV-curve, or Beveridge curve as it became known later. With this curve they determined the level of 'maladjustment' in the British economy by defining it as the level of unemployment at the equilibrium between aggregate unemployment and aggregate vacancies. This corresponds to the intersection of the empirically founded Beveridge curve and $\mathrm{U}=\mathrm{V}$ curve (or net zero demand curve), which slopes upward at 45 degrees. Unemployment above this 'maladjustment' level is considered as demand-deficient unemployment. Solow (1964) interprets this 'maladjustment' in the 'structural'-'deficient demand' debate in the USA as the level of 'structural' unemployment ( $u_{s}$ in figure 2) of which 'frictional' unemployment is a subclass. The definition of the class 'structural' unemployment has thus changed in this way from a qualitative mismatch between supply and demand for labour, to equilibrium of

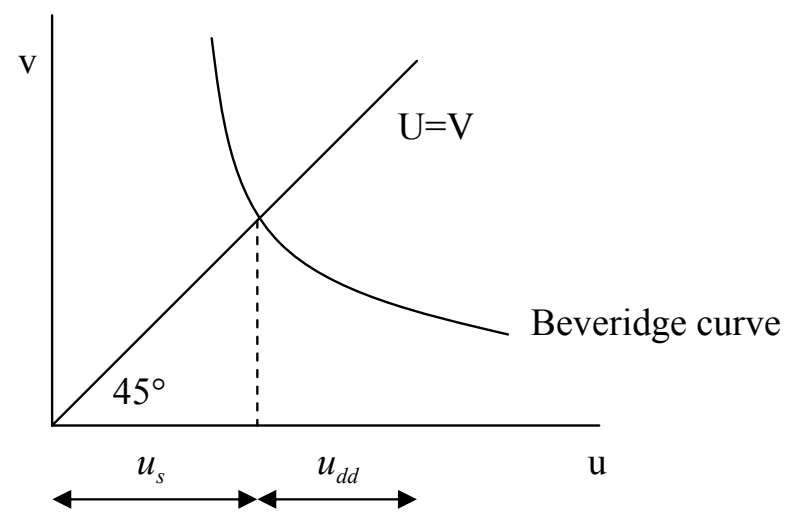

Figure 2: Structural unemployment determined by the Beveridge curve 
aggregate unemployment and aggregate vacancies. The change from a microeconomic definition to a macroeconomic definition of structural unemployment is obvious. Economists of the National Institute of Economic and Social Research (NIESR) in London also tried to identify the level of 'frictional' unemployment using this approach by determining the level of frictional unemployment as the sum of the minimum of unemployment or vacancies per sector of the economy (industry or region). Structural unemployment is defined as the sum of excess of unemployment or vacancies (which ever is the largest) per sector (Cheshire: 1973). Obviously, measurement of frictional and structural unemployment in this way requires data about vacancies and unemployment per sector of the economy (industry or region).

A definition of 'structural' unemployment based on the Phillips curve changed the interpretation of structural unemployment once more. The conceptual framework for relating 'structural' unemployment to the Phillips curve is found in Lipsey (1965) (see figure 3), where he formalises the idea of Solow and Samuelson that the Phillips curve can be seen as a policy menu. Lipsey defines full employment as the lowest level of unemployment that could be attained given the government's dual policy targets: both an acceptable rate of inflation and an acceptable rate of unemployment. These dual policy targets are represented by an indifference curve and full employment is represented where the indifference curve and the Phillips curve coincide. Unemployment above this level is considered as 'deficient demand' or 'cyclical' unemployment $\left(u_{c}\right)$ and can be lowered by expansionary fiscal policy. Once in a situation of non-deficient demand, full employment can be reached by removing 'structural'

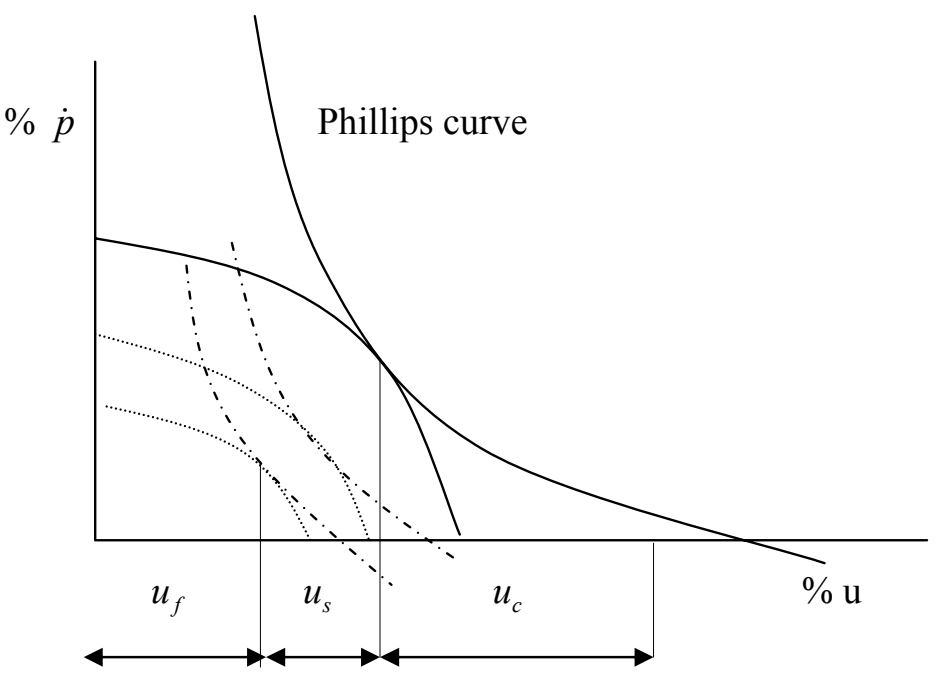

Figure 3: Classification of unemployment based on the Phillips curve 
unemployment $\left(u_{s}\right)$ until only a level of frictional unemployment $\left(u_{f}\right)$ remains. The shifts of the Phillips curve to the left could be brought about by, for example, "reducing inequalities in excess demand between various labor markets, and reducing the time taken in changing the supply of labor into the form in which it was being demanded" (Lipsey, 1965: 213). The tradeoff of costs and benefits of policy measures, such as retraining of the unemployed, determines the level of reduction of structural unemployment. Finally, the level of frictional unemployment is considered as exogenous and unavoidable. ${ }^{10}$

Muysken (1989) provides a systematic account of the classifications of unemployment in which the relations of some of the major classes of unemployment are explored. Without discussing this framework here in full detail, his final classification is presented in figure 4, showing the simultaneous existence of different analytical classes and classification schemes.

\section{Phillips curve}

Phillips curve

Beveridge curve

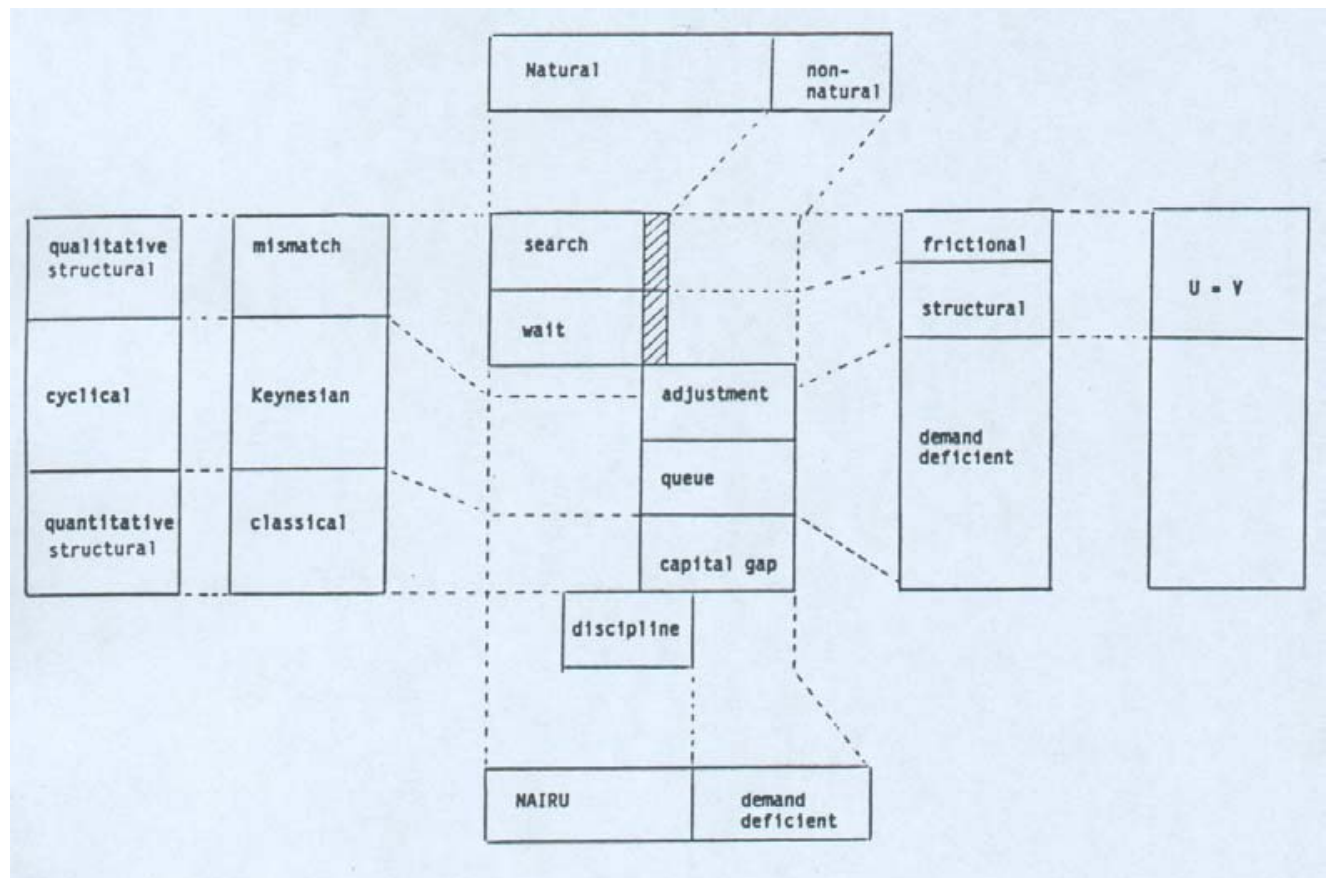

Phillips curve

Figure 4: Classifications of unemployment based on the Phillips and Beveridge curve

\footnotetext{
${ }^{10}$ In this approach, the government's indifference curve is not observable. It was however applied to test for shifts in structural unemployment by testing for shifts of the Phillips curve (see for example Vanderkamp 1966).
} 
The diagram illustrates the two alternative causal approaches to unemployment as a multipuc causal phenomenon, as mentioned in section 2, namely the microeconomic 'mechanism' approach (in the centre) and the macro 'classification' approach (at the edges). The microeconomic classes of unemployment, like search, wait and queue unemployment, are based on the use of microeconomic models of unemployment. They are centred in the middle since they are supposed to provide microeconomic foundations for the macroeconomic concepts, which are represented at the edges and rely on the 'classification approach', i.e. division based on empirical macroeconomic relations. Muysken tries to show how the macrotypes relate to the micro-types and integrates the two types of classes into one comprehensive framework. The figure shows how measurement based on the Beveridge curve yields a distinction into frictional/structural/deficient demand unemployment (shown right); measurement based on the Phillips curve yields distinctions in natural/non-natural (shown top), NAIRU/deficient demand (shown bottom), and qualitative structural/cyclical/quantitative structural unemployment (shown left). ${ }^{11}$

Unfortunately, not all 'causal' classes of unemployment fit in this classification scheme. For the classes like 'voluntary', 'involuntary' or 'Marxian' unemployment, this strategy has not been successful. Economists have not been able to relate these concepts to an observable macroeconomic relationship like the Phillips curve or the Beveridge curve, even though they are in principle macroeconomic concepts. ${ }^{12}$ The concept of 'involuntary' unemployment has a longer history in economic literature than most of the classes presented in figure 4 (see for example Boianovsky and Trautwein: 2003), but it has always been a slippery concept. We have not been able to define this concept unambiguously or to make reference to observable indicators. It is therefore no surprise to see that newer classes that are indirectly observable started to dominate the discussions on unemployment.

\section{$5 \quad$ What have we measured?}

Now what exactly is it that we have measured with this classification approach and what can we infer about the cause or causes of unemployment? The idea of the classification approach was to measure classes of unemployment in order to determine the right policy measures.

\footnotetext{
${ }^{11}$ The classification qualitative structural/cyclical/quantitative structural (left) seems equivalent to the classification structural/demand deficient/frictional (right). However, they are measured with different macroeconomic relations. They therefore have different interpretations.

${ }^{12}$ Keynes defined 'involuntary' unemployment as unemployment above the full employment level, where full employment is defined as the situation in which a further increase in aggregate demand stops reducing unemployment.
} 
However, as a consequence of the redefinition of classes in macro terms, new classes came into existences that have new meaning. The newly defined class of structural unemployment, for example, can be interpreted in different ways. Thirlwall (1969: 27) points out that at least four different interpretations for structural unemployment can be distinguished after redefining it in macro terms. ${ }^{13}$ Their new meanings are not immediately clear and are open to discussion. However, the new classes of structural unemployment have in common that they can be interpreted in terms of the various policies to reduce unemployment. Economists therefore refer to the newly established classification as a classification on a 'cure' or ex-post basis (Lipsey, 1965: 216, Thirlwall: 1969, 22). According to Thirlwall $(1969,24)$ “a 'cure' basis for classification gives ex post measures of each type of unemployment: that is, measures of the types of unemployment depending on the success of various policies in reducing unemployment within the constraints laid down", where constraints refers to the chosen policy goals. Yet, these measures do not necessarily correspond to the sets of underlying singular causes of the 'causal' classes. It can be argued that the problem of unemployment is viewed from a different perspective after redefinition and hence that the set of causes also changed. Rather than to focus on the causes of unemployment, i.e. the reasons why a worker became unemployed in the past, the attention shifts to the causes of not finding re-employment; i.e. what are the reasons an unemployed worker cannot find a new job? As Gilpatrick puts it: "The diagnosis must search for reasons for failure to re-employ experienced workers and to hire new labor-force entrants. The reasons for original disemployment are of no concern if reemployment is assured. (..) The causes blocking re-employment are the proper targets for policy." (Gilpatrick: 1966, 202). Thus while better unemployment protection for example is not a formal cause of unemployment, it becomes relevant after interpreting unemployment in terms of its cures, since new employment becomes harder to find for the unemployed after better

\footnotetext{
13 Firstly, it could be defined as "all unemployment that cannot be eliminated by expanding demand without violating the price constraint" (in a Phillips curve framework). Second, as "that amount of unemployment less minimum frictional and seasonal which cannot be removed by monetary and fiscal policy without creating substantial continuing inflation". A third interpretation is "that amount of unemployment removable through labour market policies, thus permitting the economy to operate at a higher level rate of employment without violating the price constraint". This corresponds to the movement of the Phillips curve to the left. Fourthly, it can be defined (following Lipsey) as "that amount of unemployment that can be removed by structural cures some of which pay for themselves on an analysis of the money costs and the money benefits and some of which are justified because the non-pecuniary social benefits are judged to justify the net money costs of the schemes".
} 
unemployment protection has been implemented. The single measures found in the classification approach thus refer to another set of causes.

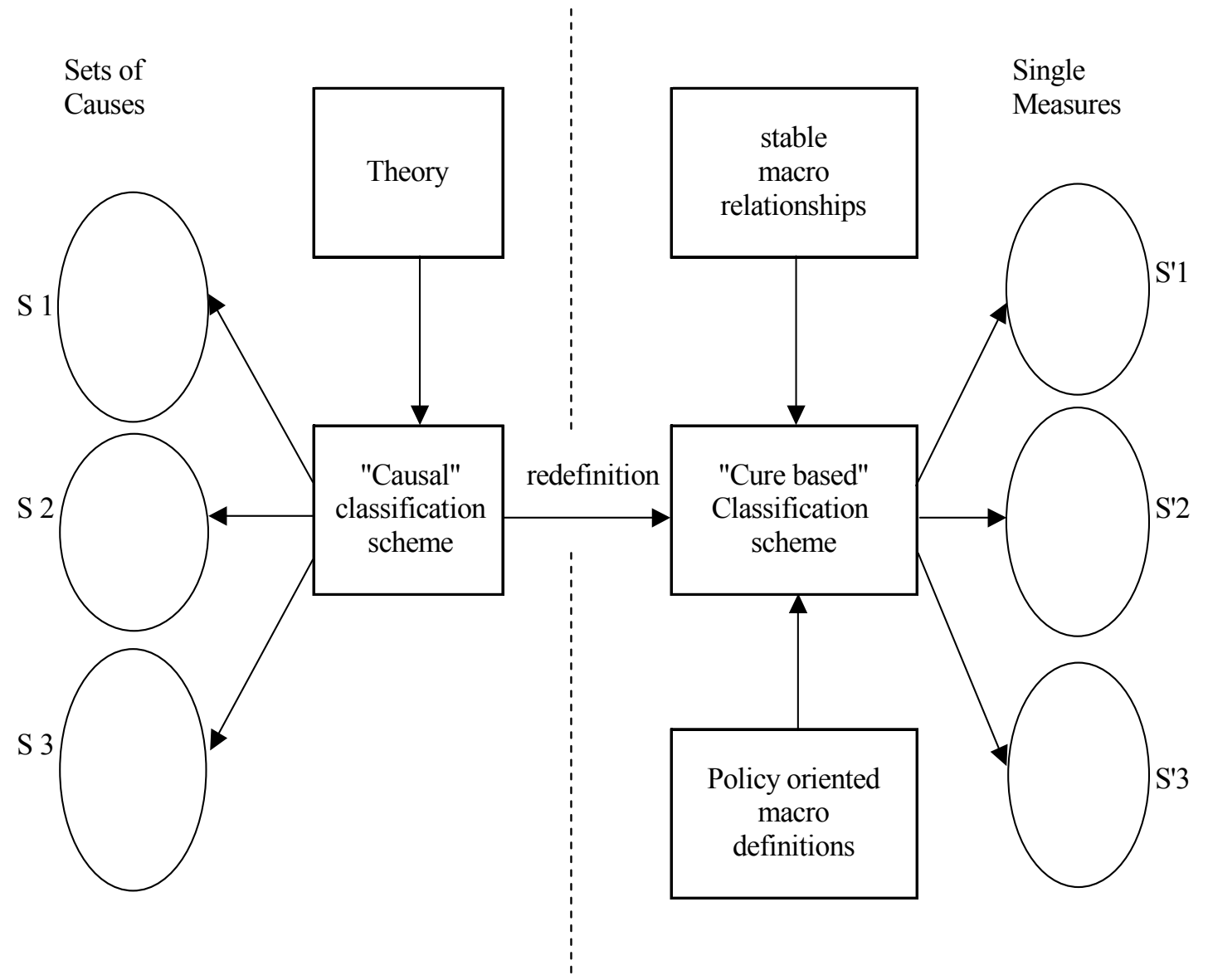

Figure 5: Measurement of analytical classes of unemployment

The measurement process of the classification approach can now be summarised as follows (figure 5). The causal classification schemes are redefined and transformed into new classes that can be measured with stable macro relationships, like the Phillips curve and the Beveridge curve. In this way the stable macro relations determine the measurement procedure used as well as the classification scheme, though additional policy oriented macro definitions are necessary to operationalise the measurement procedures. The 'causal' classification is turned into a 'cure based' classification, and the results of the measurement of these cures, i.e. the indirect, single measures (S'1-S'3) do not necessarily correspond to the sets of underlying singular causes of the 'causal' classes (S1-S3). The latter set of causes contains the causes why 
a worker became unemployed. The single measures correspond to the set of causes why a worker is 'blocked' in finding re-employment, which is obviously another set of causes.

\section{$5 \quad$ Policy measures: Back to the causes?}

The classification approach described here thus enables economists to make a kind of diagnostic analysis, more or less in the same way as doctors do. The treatment, i.e. the policy measures for fighting unemployment, follows from the diagnosis. With respect to fighting unemployment, basically three different strategies can be identified.

A first strategy for fighting unemployment is treating unemployment without knowing the underlying cause or causes. Targeting specific sectors in the economy that experience high unemployment and treating these sectors with special policies can reduce unemployment, even without knowledge about the underlying causes of the high unemployment. In this way, the 'empirical' or 'statistical' classes of unemployment obtained through classification come into play since they reveal the specific sectors in the economy that suffer from high unemployment. So, if for example the class 'unemployment in the building industry' experiences high unemployment, it can be treated by special policy measures like subsidies or employment projects for the unemployed in the building industry. In this way, it reduces unemployment without knowledge about its causes. This resembles the way doctors treat headaches or cancer. Like unemployment, headaches or cancer come about by a very complex set of causes and conditions that are seldom identified. Instead we treat the symptoms of the disease with aspirin or chemotherapy, while we remain agnostic about the underlying cause or causes of the disease.

However, this approach is not completely satisfactory. In some cases the cause or causes do matter for effective treatment. In case of toothache or eyesight problems for example, a diagnosis has to be made of what is the cause. Is it a hole in the tooth or is the root inflamed? Once the cause of the disease is determined, the appropriate treatment can be given to remove the cause of the disease, i.e. one can fill the hole or treat the root with antibiotics. For unemployment the case is quite similar: for effective policy measures it matters whether unemployment is structural or demand deficient, since the treatment for deficient demand unemployment is rather different from the treatment for structural unemployment. So, if we are able to identify the nature of unemployment, the appropriate 
policy measures for its reduction can be taken. We can think of this as the second strategy: treatment by removing the causes of the disease.

This strategy implies that we have to 'diagnose' unemployment in order to determine its nature. The classification approach described here enables economists to make this kind of diagnostic analysis. The single measures found by the classification approach correspond to the set of causes why a worker is 'blocked' in finding reemployment, not the set of causes of becoming unemployed. The causal information provided can still be used for reducing unemployment. This approach is therefore aimed at the removal of causes, even though the problem has been rephrased.

This approach has two disadvantages. First, when the measures found by the classification approach refer to a set of causes of 'blocking' re-employment, this does not provide information about which specific policy measure has to be taken. If the diagnosis shows that structural unemployment is the problem, policy measures aimed at the skills of unemployed like reschooling or retraining workers might be prescribed, though other measures might be possible as well, for example measures that affect job requirements. The classification approach does not indicate which policy measure has to be taken, or which policy measure from a set of possible measures is most effective in fighting unemployment. All it can do is 'diagnose' unemployment and suggest a set of policy measures to reduce unemployment. Secondly, redefinition of 'causal' classes into 'cure-based' classes does tacitly assume a "micro-macro compatibility" of policy measures. That is, unemployment is diagnosed at the macro level, as is the measurement of the effect of policy measures. However, the treatment might take place at the level of individuals, i.e. the micro level. From the macroeconomic interpretation of structural unemployment, measured as excess aggregate unemployment over aggregated vacancies in a UV framework, policy measures must follow aimed at reallocation of workers, such as, for example, retraining or reschooling of workers, which takes place at the level of the individual unemployed.

Finally, a third strategy with respect to fighting unemployment can be identified as the prevention of occurrence of future cases. Like better mouth hygiene can prevent tooth pain, knowledge of underlying causes of unemployment can be used to prevent unemployment occurring. Unfortunately, this is far from easy. In the first place, as explained above, causes are hard to identify. Secondly, preventing causes occurring has proven to be very difficult in practice, as can be illustrated by attempts to manage effective demand in the post war period as a means to prevent deficient demand unemployment. 
In spite of this, the prevention of unemployment is likely to be the most effective strategy in fighting unemployment. Treatment of symptoms alone is unsatisfactory. Therefore causal notions of how unemployment arises do matter and further research about causes of unemployment is needed. Unfortunately, the classification approach isn't very helpful in this respect, since it does not provide causal information on how unemployment comes about.

\section{Conclusion}

Cases of multiple causation like unemployment have proven very difficult to deal with, since the underlying causes are hard to identify. Analytical frameworks used in economics, like for example micro economic models of unemployment, do provide a framework for making causal inferences but are in a sense arbitrary and in any case partial. The models represent only one of the many mechanisms at work in the labour market and the analytical framework dictates the causal inference made. ${ }^{14}$ The problem with models always is: How well do they correspond with the real world?

Classifications can be helpful here, since economists want to reduce unemployment and therefore have to formulate economic measures. 'Statistical' classes, i.e. classes obtained by the process of classification, don't provide useful causal information but can be used to 'monitor' the economy and establish generic policy measures for specific sectors of the economy. Yet, this is simple symptomatic treatment. The 'causal' classification, obtained by the process of division, provides us with causal knowledge since we can think of these classes as being affected by a cluster of singular causes. Making these 'causal' classes indirectly measurable requires, in the first place, macroeconomic relations that economists consider stable and measurable. Secondly, a redefinition in macroeconomic terms is needed of those classes that are microeconomically defined. In this way, economists have been able to assign numbers to their outcomes in terms of a fraction or number of unemployed who fall under a particular class of unemployment. The Phillips curve and the Beveridge curve have been used to bridge the gap between unobservable properties of particulars and observable, measurable aggregate concepts. The effects of singular causes are thus not measured individually and

\footnotetext{
${ }^{14}$ For example, in the discussion on the increase in structural unemployment of the British economy after 1966, Jackman et al. $(1989,392)$ tend to conclude that the shift in structural unemployment is caused by an increase in job choosiness or a fall in search intensity. Since they use microeconomic search models of unemployment for the analysis of the phenomenon they only find causes in terms of search incentives.
} 
added up in a vector sum as Mill suggests, but singular causes are clustered together and the outcome amount of unemployment due to their joint effect is measured. In this way they avoid Mill's decomposition problem of multiple causation.

This measurement of causal classes is not without problems. A first problem is that the stable relationships economists had found, the Beveridge curve and the Phillips curve, and on which the measurement procedure relies, turned out to be unstable over time. However, in spite of this, economists still reckon these relationships to be important tools of analysis of the labour market and infer, from their shifts, changes in the compositions of causal classes of unemployment. Therefore this method is still relevant, since it at least provides measures of the change in composition of classes. And though microeconomic model building (the 'mechanism' approach) dominates contemporary labour economics, labour economists interpret shifts in the Beveridge and Phillips curves in terms of changes in the nature of unemployment, i.e. 'diagnosing'.

A second problem is that redefinition of concepts is not a neutral act. Though some classes remain unaltered in the measurement process - they were already understood in macroeconomic terms - other classes of unemployment lost their meaning after redefinition in macro terms and, consequently, had to be reinterpreted. Their new interpretation is in terms of ways of removing them, resulting in what economists refer to as a 'cure-based' classification. The causes of unemployment are now understood in terms of symptoms and the way of removing them, and the object of economic research, change likewise. Rather than researching the set of underlying causes of unemployment the attention shifted to the causes of "blocking re-employment". Hence, the theory of unemployment became, strictly speaking, a theory of employment; an approach still dominant in contemporary economic research with microeconomic models. The measurement procedure, however, enabled economists to make diagnoses, for example for policy purposes, without making specific commitment to all the 'underlying' causal mechanisms producing unemployment. In this way economists diagnose and treat the economy more or less in the same way doctors do when faced with complex multiple causal diseases. 


\section{Reference}

Benjamin, A.C., (1925), Classification and Division, The Journal of Philosophy, vol. 22, no. 17 $458-463$

Beveridge, W. (1909) Unemployment: A Problem of Industry, Longmans, Green and Co, London

Beveridge, W. (1944), Full Employment in a Free Society, George Allen \& Unwin Ltd, London

Boianovsky and Trautwein (2003), Wicksell, Cassel and the Idea of Involuntary Unemployment, (forthcoming in:) History of Political Economy, vol. 35

Boumans, M.J. (1992), A Case of Limited Physics Transfer,: Jan Tinbergen's Resources of Re-shaping Economics, Thesis Tinbergen Institute Amsterdam

Bowers, J.K., Cheshire, P.C. and Webb, A.E. (1970), The Change in the Relation between Unemployment and Earning Increases: A Review of some Possible Explanations, National Institute Economic Review, no.54, 44-63

Brown, A.J. (1976), UV Analysis, in: Worswick, G.D.N. (ed.), The Concept and Measurement of Involuntary Unemployment, George Allen \& Unwin Ltd, London

Cheshire, P.C. (1973), Regional Unemployment Differences in Great Britain, National Institute for Economic and Social Research, Regional Papers II, Cambridge University Press

Dow, J.C.R. and Dicks-Mireaux, L. (1958), The Excess Demand for Labour: A Study of Conditions in Great Britain, 1946-1956, Oxford Economic Papers, vol. 10, 1-33

Friedman, M. (1968), The Role of Monetary Policy, American Economic Review, March, no.1

Gilpatrick, E. (1966), On the Classification of Unemployment: A View on the Structural-Inadequate Demand Debate, Industrial and Labor Relations Review, vol. 19, no. 2, 201-212

Hollinger, R. (1976), Aspects of the Theory of Classification, Philosophy and Phenomenological Research, vol. 36, no. 3, 319-338

Hoover, K.D. (2001), Causality in Macroeconomics, Cambridge University Press

Hughes J.J. and Perlman, R. (1984), The Economics of Unemployment, A Comparative Analysis of Britain and the United States, Wheatsheaf Books LTD, Brighton

Lipsey, R.G. (1965), Structural and Deficient-demand Unemployment Reconsidered, in: McCormick, B.J. and Owen Smith E. (eds.), The Labour Market, Hammondsworth, 245-269

Machamer, P., Darden, L. and Craver, C.F. (2000), Thinking about Mechanisms, Philosophy of Science, vol. 67, March, p 1-25

Malinvaud, E. (1977), The Theory of Unemployment Reconsidered, Basil Blackwell, Oxford

Malinvaud, E. (1994), Diagnosing Unemployment, Cambridge University Press 
Mill, J.S. (1925), A System of Logic, Longman, Green, and Co., London

Morgan, M.S. (1990), The History of Econometric Ideas, Cambridge University Press

Muijsken, J. (1989), Classification of Unemployment: Analytical and Policy Relevance, De Economist, vol. 137, no. 4

Phelps, E. (1967), Phillips curves, expectations of inflation, and optimal unemployment over time, Economica, 34, August, p. 254-81

Pigou, A.C. (1933), The Theory of Unemployment, Macmillan, London

Rodenburg, P. (2002), The Beveridge Curve as a Tool of Analysis: A Survey of the UVRelationship, unpublished working paper

Sokal, R.R. (1974), Classification: Purposes, Principles, Progress, Prospects, Science, vol. 185, no. $4157,1115-1123$

Solow R.M. (1964), The Nature and Source of Unemployment in the United States, (Wicksell Lecture 1964) Almqvist \& Wiksell, Stockholm

Thirlwall, A.P. (1969), Types of Unemployment, with Special Reference to "Non-Demand Deficient" Unemployment in the UK, Scottish Journal of Political Economy, vol. 16, no. 1

Vanderkamp, J. (1966), An application of Lipsey's Concept of structural unemployment, The Review of Economic Studies, vol. 33, no. 3, 221-225

Webb, A.E. (1974), Unemployment, Vacancies and the Rate of Earnings: A Regional Analysis, National Institute of Economic and Social research, Regional Papers III, Cambridge University Press

Worswick, G.D.N. (ed.) (1975), The Concept and Measurement of Involuntary Unemployment, George Allen \& Unwin Ltd., London 